\title{
A TIPOGRAFIA EM LIVRO DIGITAL COM RECURSO DE REALIDADE VIRTUAL: ANÁLISE DO APLICATIVO "PERÔNIO".
}

\section{TYPOGRAPHY IN DIGITAL BOOK WITH VIRTUAL REALITY: ANALYSIS OF THE APPLICATION “PERÔNIO”.}

\author{
Maíra Woloszyn ${ }^{1}$, Bela. \\ Berenice Santos Gonçalves², Dra. \\ (1) Universidade Federal de Santa Catarina \\ e-mail: maira.projetar@gmail.com \\ (2) Universidade Federal de Santa Catarina \\ e-mail:berenice@cce.ufsc.br
}

Livro digital; Realidade virtual; Tipografia

Os livros digitais passaram a oferecer novas possibilidades em suas interfaces, como recursos de realidade virtual. Nesse sentido, o presente artigo tem por objetivo verificar como a tipografia participa dos processos de interação em um livro com tecnologia de realidade virtual. Para tanto, adotou-se procedimentos analíticos a partir da abordagem de Tori e Kirner (2006). Os resultados mostram que a aplicação da tipografia comprometeu a legibilidade e leitura de alguns trechos de texto, como os que trazem instruções de navegação e manipulação para o leitor.

\section{Digital book; Virtual reality; Typography}

Digital books began to offer new possibilities in their interfaces, such as virtual reality features. In this sense, this paper aims to verify how typography participates in the processes of interaction in a book with virtual reality technology. Therefore, was adopted analytical procedures based on Tori and Kirner (2006) approach. The results show the application of typography compromised the legibility and readability of some text segments, such as those that provide navigation and manipulation instruction to the reader.

\section{Introdução}

A partir dos avanços nas interfaces gráficas, tendo em vista a evolução da internet, dos recursos interativos e a chegada de novos dispositivos de acesso, os aspectos da interação humano- computador vêm sendo modificados (ROGERS; SHARP; PREECE, 2013). Junto a isso, a popularização dos dispositivos móveis também permitiu a ampliação de experiências para o usuário com produtos interativos, bem como gerou novas necessidades para garantir a usabilidade dos produtos digitais. Para Rogers, Sharp e Preece
Realização:
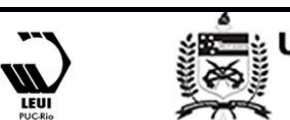


\section{$16^{\circ}$ \\ ERGODESIGN USIHC CINAHPA}

(2013) a usabilidade é um fator que assegura que estes produtos sejam fáceis de usar, eficientes e agradáveis, e implica em otimizar as interações a fim de permitir que os usuários realizem suas atividades.

Quanto aos modos de interação, que corresponde a ação dos usuários com elementos disponíveis, Rogers, Sharp e Preece (2013), apresentam quatro possibilidades: (i) instrução, corresponde a possibilidade de emitir instruções ao sistema por meio de comandos textuais, de voz, gestos ou toque de teclas; (ii) conversação, referente à forma de trocar informações baseada em perguntas e respostas; (iii) manipulação, possibilidade de interagir com objetos em espaços virtuais ou físicos manipulando os elementos, como abrir, mover, segurar e fechar; e (iv) exploração, referente às opções oferecidas para a movimentação do usuário em ambientes de realidade virtual e realidade aumentada.

O desenvolvimento tecnológico também facilitou o surgimento de uma nova forma de comunicação, o que muda a maneira como se vê os livros hoje. Considerado um dos bens mais importantes de humanidade, o livro vem sendo ampliado nos meios digitais, onde os modos de leitura são dinâmicos, descentralizados e interativos (SILVA; BORGES, 2012).

Com isso, novas possibilidades para as publicações editoriais surgiam e, devido ao potencial oferecido pelos dispositivos móveis, foi possível oferecer aos leitores diferentes opções: epubs, app books e até mesmo, livros com possibilidades de expansão para a realidade virtual e aumentada. Estes dois últimos recursos têm se mostrado cada vez mais possível por conta da redução de custos de implementação, da disseminação do conhecimento das tecnologias e do aumento significativo de possibilidades de uso (ACIOLY et. al, 2014).

Diante desse contexto, da popularização tanto da tecnologia empregada à realidade virtual, quanto dos dispositivos móveis, identifica-se a necessidade de compreender a interações nesses ambientes e de avaliar as limitações e potencialidades dos recursos gráficos que $16^{\circ}$ Ergodesign - Congresso Internacional de Ergonomia e Usabilidade de Interfaces Humano Tecnológica: Produto, Informações Ambientes Construídos e Transporte

$16^{\circ}$ USIHC - Congresso Internacional de Ergonomia e Usabilidade de Interfaces Humano Computador

CINAHPA | 2017 - Congresso Internacional de Ambientes Hipermídia para Aprendizagem.

compõem os livros digitais que dispõem de recursos de realidade virtual, em especial à tipografia, uma vez que, apesar da comunicação digital ter dado especial realce à elementos gráficos e audiovisuais, o texto ainda é o que sustenta as peças informativas, mesmo que a partir de uma leitura fragmentada (SALAVERRÍA, 2014). Sendo assim, o presente artigo tem como pergunta norteadora: como a tipografia participa na interação em um livro com recurso de realidade virtual?

Para tanto, essa pesquisa propõem a análise de um exemplar de livro com recurso de realidade virtual com base na abordagem de Tori e Kirner (2006) sobre a interação neste ambiente. Assim, esta pesquisa pode ser classificada de acordo como a sua natureza como aplicada. Quanto aos objetivos, caracteriza-se como descritiva, pois visa descrever características observadas na análise do objeto de estudo. E, quanto aos procedimentos metodológicos, caracteriza-se como bibliográfica e analítica (PRODANOV; FREITAS, 2013).

\section{Livro e tecnologia digital}

O livro digital ainda é um artefato recente na cultura de leitura do país. Apesar de começar a ser discutido em 2007, com o surgimento do dispositivo de leitura kindle da empresa Amazon, o grande salto de vendas deste produto aconteceu somente em 2012 (PINSKY, 2013). Já para Caldwell e Zapaterra (2014), foi com a chegada do iPad, em 2010, que o design editorial foi inserido no contexto dos ambientes digitais e dos dispositivos móveis, o que permitiu à designer e editores incluir interatividade em suas publicações.

Para Murray (2003), os ambientes digitais possuem quatro características essenciais. Assim, os ambientes digitais são procedimentais, participativos, espaciais e enciclopédicos. São procedimentais pois possuem a capacidade de executar uma série de regras e incorporar comportamentos complexos e aleatórios. Participativos, por serem capazes de reconstituir respostas comportamentais codificadas, respondendo a comandos, e de serem interativos. Espaciais, pois são espaços navegáveis e
Realização:

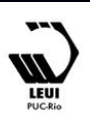




\section{$16^{\circ}$ \\ ERGODESIGN USIHC CINAHPA}

apresentam um espaço pelo qual os usuários podem se mover. E enciclopédicos, pela possibilidade de armazenamento e recuperação de grandes quantidades de informação, como em uma enciclopédia, com recursos infinitos.

Ao serem configuradas para os ambientes digitais, as publicações introduziram uma mudança de paradigma diferente da cultura das publicações impressas. Enquanto nos livros tradicionais os formatos, por exemplo, eram definidos pelo editor e designer, no meio digital quem pode fazer essa escolha é o usuário ao optar por ler o conteúdo em um smartphone, tablet, computador de mesa, entre outros (BRUJIN; et. al, 2015).

A produção, distribuição e a leitura dos livros também foi alterada com os livros digitais. Com as novas tecnologias de informação e comunicação no contexto das publicações editoriais, houve uma mudança tanto na alfabetização do leitor quanto uma mudança de paradigma organizacional da indústria do livro (SILVA; BORGES, 2012). Os livros, que, quando impressos, necessitavam de estoque, agora estão disponíveis à qualquer lugar do mundo, à qualquer hora e à custos mais baixos que as vendas locais (PINSKY, 2013).

Ainda, para Silva e Madureira (2009) os livros digitais transformaram a forma de leitura.

Conforme Santaella (2013), apesar de semelhantes, as experiências de leitura em meio impresso e digital são distintas, uma vez que os dispositivos digitais oferecem interações diferentes daquelas oferecidas pelo folhear do papel.

Para Baron (2015), há dois modos de leitura relacionado aos meios digitais, a "leitura fragmentada" (reading on the prowl) e "leitura contínua" (continuous reading). A primeira, leitura fragmentada, sugere uma leitura não tradicional, onde os leitores buscam apenas as informações às quais lhe convém, similar à uma varredura dos textos. Já a leitura contínua oferece oportunidade para o que pode ser chamado de leitura profunda (deep reading), conceito cunhado por Sven Birkerts, em 1994, que o define como a posse lenta e meditativa do livro. Ainda, pode ser entendido como um processo que proporciona a compreensão $16^{\circ}$ Ergodesign - Congresso Internacional de Ergonomia e Usabilidade de Interfaces Humano Tecnológica: Produto, Informações Ambientes Construídos e Transporte

$16^{\circ}$ USIHC - Congresso Internacional de Ergonomia e Usabilidade de Interfaces Humano Computador

CINAHPA | 2017 - Congresso Internacional de Ambientes Hipermídia para Aprendizagem.

e incluí raciocínio inferencial e dedutivo além de análise crítica e reflexão (SILVA; MADUREIRA, 2009; BARON, 2015).

Por conta disso, livros de diferentes categorias tem se adequado ao ambiente digital conforme as potencialidades interativas, em especial os livros infantis. Teixeira (2015) pontua que recursos como sensores de movimento, orientação, localização, interação com a câmera e a tecnologia touch screen tornaram os dispositivos móveis mais atrativos que a interação mediada por mouse e teclado. Desta forma, os livros digitais interativos infantis mesclam características do livro impresso infantil com games e animações permitindo a criação de histórias mais complexas e atrativas.

Nesse sentido, o livro digital pressupõe a existência de diversas possibilidades não encontradas no meio impresso, incorporadas ao próprio produto, como a multimídia (PINSKY, 2013). Conforme Ribeiro (2012), multimídia é a combinação, mediada por computador, de diferentes mídias que possam representar, armazenar, transmitir e processar uma informação de forma digital.

Para o autor, é possível destacar cinco características principais associadas à multimídia: (i) representação digital, característica essencial onde a informação é representada de maneira digital, a partir de códigos binários; (ii)

combinação de mídias, devem combinar pelo menos um tipo de mídia estática (texto, gráficos ou imagens), com pelo menos um tipo de mídia dinâmica (vídeo, áudio ou animação); (iii) sistema controlado por computador, implica em, pelo menos a apresentação final, seja feita a partir do meio digital; (iv) integração, aspecto essencial que requer que todas as mídias estejam integradas para que possam ser apresentadas através de uma única interface; e (v) interatividade, a interface final pode permitir ao usuário interagir com o conteúdo.

Com as possibilidades oferecidas pela multimídia, o livro está se reconfigurando com o apoio de recursos e facilidades oferecidas pela tecnologia, buscando reproduzir a essência, já consagrada, dos livros impressos em meios digitais, agregando
Realização:

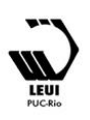




\section{$16^{\circ}$ \\ ERGODESIGN USIHC CINAHPA}

$16^{\circ}$ Ergodesign - Congresso Internacional de Ergonomia e Usabilidade de Interfaces Humano Tecnológica: Produto, Informações Ambientes Construídos e Transporte

$16^{\circ}$ USIHC - Congresso Internacional de Ergonomia e Usabilidade de Interfaces Humano Computador

CINAHPA | 2017 - Congresso Internacional de Ambientes Hipermídia para Aprendizagem. novas funcionalidades que geram maior interação do leitor com o conteúdo (VIRGÍNIO; ALMEIDA, 2014). Nesse sentido, percebe-se, atualmente, que o recurso tecnológico da realidade virtual também tem ganhado espaço no âmbito editorial.

\subsection{Realidade virtual como recurso tecnológico aplicado à livros digitais}

A realidade virtual (RV) é compreendida como uma "interface avançada do usuário" que tem como características a visualização e interação com ambientes RV. Ela permite aos usuários interagir com situações imaginárias, cenários fictícios, objetos virtuais estáticos ou em movimento. Com a realidade virtual também é possível reproduzir com fidelidade ambientes da vida cotidiana, como o ambiente interno de uma casa e até mesmo uma cidade virtual. (TORI; KIRNER, 2006)

$\mathrm{O}$ ambiente de realidade virtual pode assumir várias formas: estar baseado no mundo real, ou não apresentar referências a ele. Os objetos que compõem este ambiente "terão certos atributos à eles associados como: a geometria, cores, texturas, iluminação, características dinâmicas, restrições físicas e atributos acústicos" (TORI, KIRNER, 2006, p.10).

A interação no mundo virtual acontece a partir de interfaces intuitivas para o usuário e envolvem diversas ações como voar, pegar objetos, utilizar gestos para comandar o sistema, entre outros. "O usuário pode simplesmente observar o funcionamento do ambiente de realidade virtual simulado animado, tendo uma experiência passiva, ou ser o agente do sistema, interferindo em seu funcionamento" (TORI; KIRNER, 2006, p.14). Além de interações individuais, os ambientes RV permitem a interação entre varias pessoas através de sistemas multiusuários.

Conforme Tori e Kirner (2006), as interações do usuário nesses ambientes abrangem navegação, seleção, manipulação e controle do sistema.

A navegação se refere ao movimento do usuário no ambiente RV, e envolve, além da movimentação mecânica, a definição do trajeto, que é a componente cognitiva da navegação. Pode ser utilizada para explorar, buscar e manobrar, envolvendo a escolha da direção, velocidade e ações de início, sentido e parada do movimento.

A seleção consiste na escolha do objeto a ser manipulado e envolve três passos: (i) indicação do objeto, feita a partir de toques no objeto, apontamento ou de maneira indireta; (ii) confirmação da seleção e (iii) realimentação, indicação de que a ação ocorreu.

A manipulação incide na alteração do objeto, seja da sua posição, por translação ou rotação, ou na sua aparência, com mudanças de escala, cor, transparência e textura.

E, por fim, o controle do sistema está relacionado à emissão de comandos do usuário, através de menus gráficos, comandos de voz e gestos, entre outros, a serem executados pelo sistema.

No entanto, para interagir com os ambientes RV, é necessário fazer uso de algum aparato tecnológico como luvas, óculos, entre outros (TORI; KIRNER, 2006). Atualmente, existem algumas iniciativas que permitem o fácil acesso à realidade virtual, como é o caso do google cardboard, óculos de realidade virtual proposto pela Google, confeccionado com papelão.

O google cardboard traz experiências imersivas de forma simples e acessível (GOOGLE, 2016), e a empresa disponibiliza para download gratuito a matriz de confecção do produto. Ainda, é possível encontrar o produto pronto, já montado, a preços acessíveis. O acessório funciona a partir de um smartphone, de até 6 polegadas, que serve como processador dos aplicativos que dispõem da funcionalidade RV.

Com iniciativas como a da Google, juntamente com a redução dos custos de implementação, a realidade virtual se mostra cada vez mais aplicável. A realidade virtual pode estar inserida em diversos contextos, como indústria, entretenimento, educação, e em diversos tipos de aplicação, como protótipos virtuais e os próprios livros digitais. 
$16^{\circ}$ Ergodesign - Congresso Internacional de Ergonomia e Usabilidade de Interfaces Humano Tecnológica: Produto, Informações Ambientes Construídos e Transporte

$16^{\circ}$ USIHC - Congresso Internacional de Ergonomia e Usabilidade de Interfaces Humano Computador

CINAHPA | 2017 - Congresso Internacional de Ambientes Hipermídia para Aprendizagem.

\section{Tipografia em ambientes digitais}

Os aspectos das publicações, de modo geral, são baseados nas necessidades de leitura e compreensão da informação apresentada, mesmo em publicações onde as imagens prevalecem, $o$ refinamento do texto é necessário para garantir o sucesso do produto (SAMARA, 2011).

Responsável por conferir forma ao texto, a literatura referente a tipografia possui algumas diretrizes de configuração a fim de facilitar a leitura e compreensão das informações apresentadas.

Compreendida como a área que estuda a história, anatomia, desenvolvimento e uso dos tipos, Farias (2004) entende a tipografia como a prática e o processo envolvidos na criação e utilização de símbolos ortográficos e para-ortográficos. Para Royo (2008), a tipografia em meio digital possui características de aplicação que podem ser regidas por três regras. A primeira é legibilidade e contraste. Para o autor (2008), o tipo de letra deve ser visualizado com clareza e o controle do contraste entre as formas e os espaços vazios é fundamental para obter legibilidade. Outros fatores também influenciam na legibilidade como o contorno dos glifos, o estilo da fonte escolhida, a cor aplicada às letras e contraste com o plano de fundo. Nesse sentido, Farias (2013) ainda faz a distinção da legibilidade e leiturabilidade. $\mathrm{O}$ primeiro, conforme apontado por Royo (2008), diz respeito à clareza dos caracteres em si, ou seja, a forma das letras, já a leiturabilidade está relacionada com o conforto de leitura de um texto como um todo (FARIAS, 2002). Assim, alguns fatores que afetam a leiturabilidade são o comprimento de linha, espaçamento entre linhas, alinhamento dos blocos de texto e tamanho da fonte aplicada ao texto.

A segunda regra, é a hierarquia de informação. Conforme Royo (2008), títulos, subtítulos, imagens e outros tipos de texto precisam apresentar configurações diferentes para que o leitor possa distingui-los com facilidade. Schlatter e Levinson (2013) acrescentam que contrastes na tipografia são a chave para criar hierarquia, que pode ser alcançada apenas com variações nos tamanhos e peso dos tipos1. Conforme Kalbach (2009), desta forma é possível apresentar as opções de navegação e guiar o leitor pelo conteúdo.

Por fim, a terceira regra, é a coordenação gráfica ou consistência. Para Royo (2008), se a aparência dos textos é integrada com a aparência do sistema, o usuário se sentirá mais confortável e terá a sensação de controle. Nesse sentido, Schlatter e Levinson (2013) afirmam que, a tipografia é um componente importante da personalidade de uma interface ou de um sistema. A sua percepção, junto aos demais elementos, pode ser influenciada pelo layout, cores, assim como pelas referencias visuais dos usuários. Sendo assim, as autoras ressaltam que a tipografia escolhida para uma interface deve refletir o objetivo e as características do produto.

Além disso, ao ponderar a tipografia no universo dos produtos infantis, pesquisas apontam a necessidade de considerar as capacidades cognitivas e motoras das crianças e o conforto de leitura para garantir a legibilidade das letras (HITLINGER, 2007). Em vista disso, alguns parâmetros podem ser ajustados, como o desenho dos caracteres, que podem ser ajustados a fim de serem semelhantes a letras manuscritas e fáceis de serem distinguidos entre si. Além disso, características como ascendentes e descentes ${ }^{2}$ longas e uma aparência "amigável" podem motivar a leitura no universo infantil. Também, o espaçamento entrelinhas deve permitir que a criança acompanhe a linha que está lendo, sem que deslizem para as seguintes (WALKER, 2005).

Além de garantir conforto de leitura e legibilidade, a tipografia também pode assumir outras funções. Para Caldwell e Zappaterra (2014), a tipografia também pode ser vista como uma forma de expressão, principalmente em publicações que não apresentam imagem, mas que necessitam expressar algo além do conteúdo. Nesse contexto, a

\footnotetext{
${ }^{1}$ As famílias tipográficas são compostas por um conjunto de fontes que apresentam variações principalmente de peso - variação nos tamanhos das hastes de modo geral -, como light, medium, bold e black, e variação entre tipos romanos e itálicos

${ }^{2}$ As ascendentes e descendentes são as partes das letras minúsculas que se prolongam acima e abaixo da altura-x.
}

Realização:

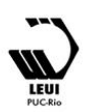




\section{$16^{\circ}$ \\ ERGODESIGN USIHC CINAHPA}

tipografia também pode ser explorada para conferir personalidade e associar outros significados aos textos.

Ainda, Pinheiro (2012) entende que o uso da tipografia pode ser visto a partir de duas formas. A primeira, em relação aos aspectos da aplicação tipográfica, buscando a legibilidade e leiturabilidade dos textos. A segunda, quanto aos aspectos ligados ao estilo da tipografia e os significados trazidos por seu desenho e suas formas, podendo clamar por uma condição de "arte".

Nos meios digitais, a tipografia ainda pode assumir a função de navegação. Lupton (2015, p.106) explica que "um caminho é uma rota consistente e previsível que conecta o conteúdo", que pode surgir tanto dos próprios hábitos do usuário como da criação do desenvolvedor a partir de elementos textuais de navegação. Para Lupton (2015), a tipografia como navegação pode acontecer como:

(i) links de texto, palavras ou expressões que direcionam o usuário para outros locais e utilizam da variação de estilos e cores para identificar sua presença; (ii) navegação estrutural, mostra ao usuário a sua localização dentro dos caminhos; (iii) links de âncora, direcionam o usuário para um local específico na mesma página; e (iv) tags, frequentemente encontrados em blogs criam uma espécie de índice para cada página.

Sendo assim, identifica-se a necessidade de avaliar a tipografia em publicações digitais a fim garantir a clareza do conteúdo apresentado. Um sistema avaliativo é proposto por Lupton (2015) juntamente com Christopher Clark com o objetivo de apoiar a escolha de fontes para os desenvolvedores de produtos digitais, que é feita de acordo com: legibilidade, flexibilidade, elegância, leitura, carisma e adaptabilidade. $16^{\circ}$ Ergodesign - Congresso Internacional de Ergonomia e Usabilidade de Interfaces Humano Tecnológica: Produto, Informações Ambientes Construídos e Transporte

$16^{\circ}$ USIHC - Congresso Internacional de Ergonomia e Usabilidade de Interfaces Humano Computador

CINAHPA | 2017 - Congresso Internacional de Ambientes Hipermídia para Aprendizagem.

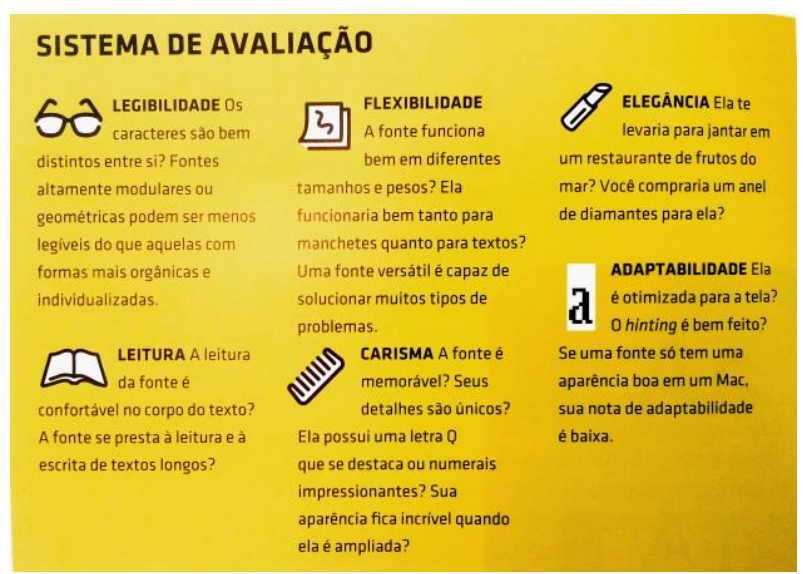

Figura 1. Sistema avaliativo proposto por Lupton e Clak. Fonte: Lupton (2015, p.20)

A legibilidade, conforme abordado anteriormente, diz respeito à clareza dos caracteres. A

flexibilidade trata da versatilidade da fonte, se ela se adapta bem à diversos tamanho de letra e à diversas funções, como título, corpo de texto, notas de rodapé, etc. A elegância diz respeito sobre o desenho das letras, e da sua integração com o produto. A leitura está ligada a leiturabilidade, se a fonte e o tamanho empregado possibilitam uma leitura confortável. O carisma, assim como a elegância, está relacionado ao desenho das letras. E, por fim, a adaptabilidade se refere à otimização da fonte para aplicação em meios digitais.

\section{Procedimentos metodológica}

Os procedimentos adotados foram estruturados conforme mostra a figura a seguir.

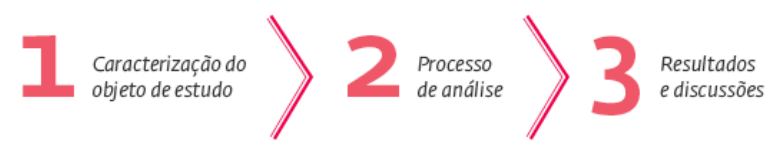

Figura 2. Procedimentos metodológicos. Fonte: Elaborado pelas autoras.

$\mathrm{O}$ esquema mostra as etapas que foram organizadas da seguinte forma: 1. Apresentação do objeto de estudo, 2. Processo de análise, e 3. Organização e discussão dos resultados obtidos na análise. 


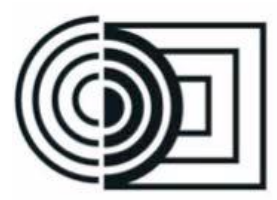

$16^{\circ}$ Ergodesign - Congresso Internacional de Ergonomia e Usabilidade de Interfaces Humano Tecnológica: Produto, Informações Ambientes Construídos e Transporte

$16^{\circ}$ USIHC - Congresso Internacional de Ergonomia e Usabilidade de Interfaces Humano Computador

CINAHPA | 2017 - Congresso Internacional de Ambientes Hipermídia para Aprendizagem.

\subsection{Caracterização do objeto de estudo:}

Com o objetivo de verificar como ocorre a participação da tipografia na interação de livros com recurso de realidade virtual, um exemplar foi selecionado como objeto de estudo. O livro escolhido para análise foi o "Perônio - What do you want to be?", livro digital com recursos de realidade virtual e aumentada desenvolvido pela empresa brasileira "Ovni Studios".

O livro aplicativo foi finalista na categoria de jogo educacional do BIG Festival 2015, e venceu o Vuforia Awards, premiação promovida pela Qualcomm para desenvolvedores em plataforma Unity. O aplicativo pode ser visualizado de três formas: como um livro interativo para smartphone, como um livro de realidade virtual com o apoio do google carboard e como um título de realidade aumentada com o auxílio da câmera do smartphone, conforme mostra a primeira tela do aplicativo, na figura 3. Para a análise deste estudo, a ótica do livro será apenas a de livro de realidade virtual.

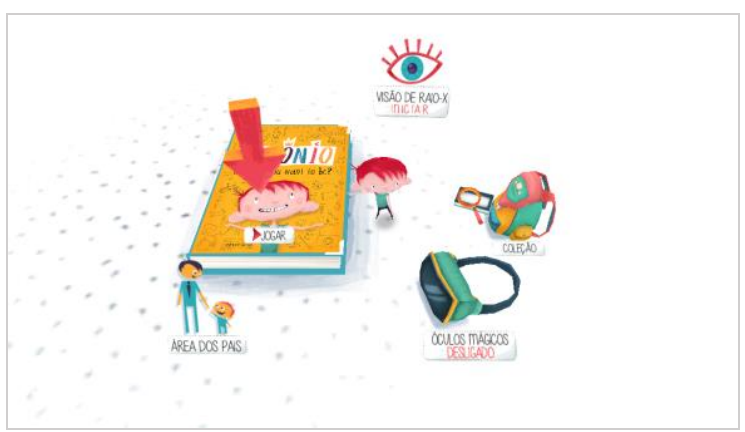

Figura 3. Abertura do aplicativo. Fonte: captura de tela do aplicativo "Perônio".

O livro mostra a história de Perônio, um personagem que conhece diferentes profissões para saber o que quer ser quando crescer. De médico à arqueólogo, o usuário conhece de maneira didática as diferentes ocupações abordadas pelo livro.

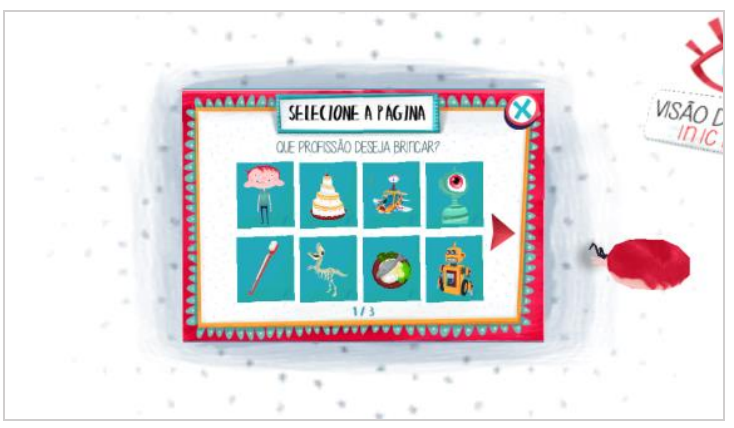

Figura 4. Interior do livro. Fonte: captura de tela do aplicativo "Perônio".

O livro é divido em 21 partes, incluindo a introdução. Cada parte diz respeito à uma das cinco profissões - chef de cozinha, engenheiro, astronauta, dentista e arqueólogo - com diferentes interatividades.

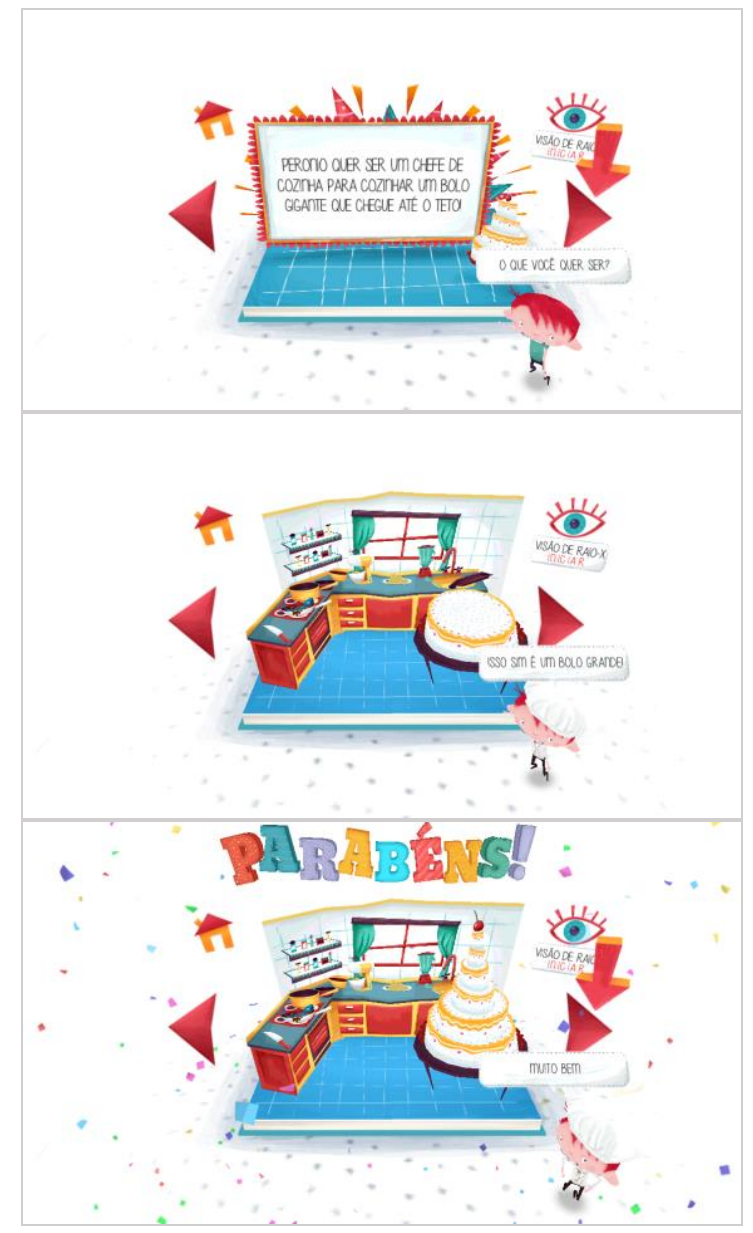

Figura 5. Interior do livro, sessão "chef de cozinha". Fonte: captura de tela do aplicativo "Perônio".
Realização:

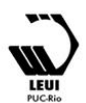




\section{$16^{\circ}$ \\ ERGODESIGN USIHC CINAHPA}

Uma vez que a função da tipografia se repete em todas as partes, para a análise, optou-se por selecionar a parte do livro que trata da profissão chef de cozinha, com a atividade de "cozinhar um bolo", apresentados na figura acima, a fim de verificar a participação da tipografia na interação com o ambiente de realidade virtual.

\section{Resultados e discussões}

A análise foi estruturada a partir das abordagens sobre interação no ambiente de realidade virtual de Tori e Kirner (2006), que abrange: navegação, seleção, manipulação e controle do sistema. A síntese dos resultados identificados na análise do aplicativo "Perônio" acessado a partir de recursos de realidade virtual pode ser visualizada no quadro a seguir.

\begin{tabular}{ll} 
FORMAS DE & PARTICIPAÇÃO DA TIPOGRAFIA \\
INTERAÇÃO & \\
& $\begin{array}{l}\text { Orientada principalmente por ícones. A } \\
\text { tipografia se apresenta na navegação como } \\
\text { instruções expressas em pequenos } \\
\text { fragmentos de texto. }\end{array}$ \\
\hline
\end{tabular}

Seleção Orientada apenas por ícones.

Manipulação Orientada por textos associados à ícones.

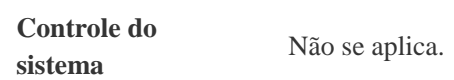

Quadro 1. Síntese da análise do livro "Perônio". Fonte: elaborado pelas autoras.

\section{Navegação}

A navegação no produto é orientada principalmente por ícones de setas que indicam os caminhos por onde o usuário pode percorrer no livro. A tipografia no sentido de navegação aparece principalmente a partir dos fragmentos de textos que "contam a história" de Perônio, e das orientações da atividade a ser realizada. $16^{\circ}$ Ergodesign - Congresso Internacional de Ergonomia e Usabilidade de Interfaces Humano Tecnológica: Produto, Informações Ambientes Construídos e Transporte

$16^{\circ}$ USIHC - Congresso Internacional de Ergonomia e Usabilidade de Interfaces Humano Computador

CINAHPA | 2017 - Congresso Internacional de Ambientes Hipermídia para Aprendizagem.

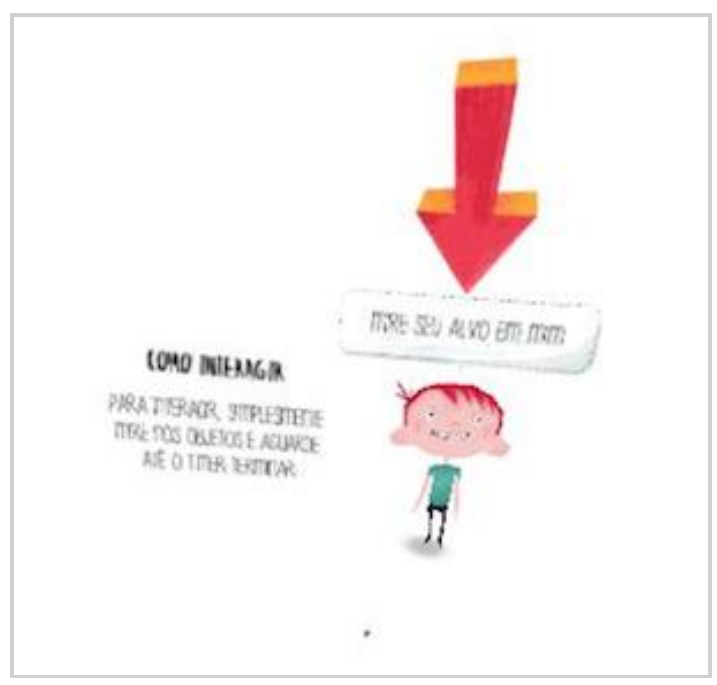

Figura 6. Instruções de navegação. Fonte: captura de tela do aplicativo "Perônio".

\section{Seleção}

Da mesma forma, a seleção, nas três etapas indicação do objeto, confirmação e realimentação -, é orientada a parir de ícones e setas.

\section{Manipulação}

A manipulação, por sua vez, é orientada a partir de textos juntamente com ícones, como é observado no botão "visão raio-X", apresentado na imagem a seguir.

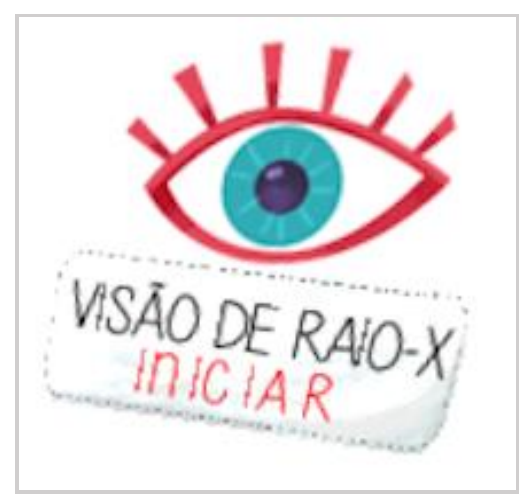

Figura 7. Botão Visão de Raio-X. Fonte: captura de tela do aplicativo "Perônio".

Entretanto, na visualização a partir do recurso de realidade virtual, pelo tamanho das letras ser menor, a leitura desta indicação se torna ilegível.
Realização:
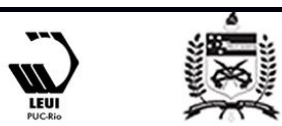


\section{$16^{\circ}$ \\ ERGODESIGN USIHC CINAHPA}

$16^{\circ}$ Ergodesign - Congresso Internacional de Ergonomia e Usabilidade de Interfaces Humano Tecnológica: Produto, Informações Ambientes Construídos e Transporte

$16^{\circ}$ USIHC - Congresso Internacional de Ergonomia e Usabilidade de Interfaces Humano Computador

CINAHPA | 2017 - Congresso Internacional de Ambientes Hipermídia para Aprendizagem.
De toda a forma, o botão proporciona mudar a cor de fundo da interface, tornando-a escura, conforme mostra a figura a seguir.

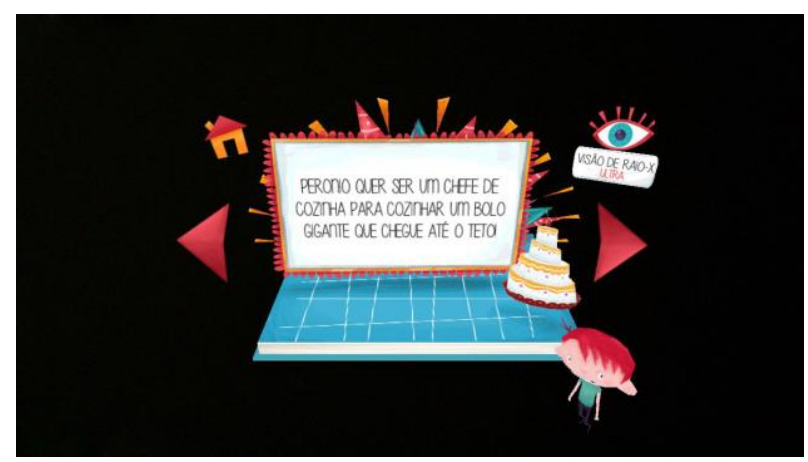

Figura 8. Botão "Visão Raio-X" acionado. Fonte: captura de tela do aplicativo "Perônio".

\section{Controle do sistema}

Por fim, a tipografia não faz parte do processo de interação referente ao controle do sistema, uma vez que trata da emissão de comandos do usuário para o sistema executar.

\section{Discussões}

A partir da análise da participação da tipografia na interação do livro digital com recurso de realidade virtual, foi possível observar que, de modo geral, este recurso torna os caracteres imprecisos, principalmente aqueles com tamanhos menores. Sendo assim, compromete a legibilidade e a leitura de alguns trechos de texto, como os que trazem instruções de navegação e manipulação para o leitor.

Quanto a fonte escolhida para compor a interface do livro, pode-se inferir que ela apresenta carisma e elegância, uma vez que está de acordo com a linguagem gráfica do produto como um todo. Além disso, a fonte permite a integração dos textos com os demais elementos presentes na interface.

Entretanto, a fonte não apresenta flexibilidade, pois não possui o mesmo desempenho em diferentes tamanhos, bem como em diferentes funções de texto - corpo de texto e textos auxiliares. Ainda, a adaptabilidade da fonte, ou seja, sua otimização para visualização na tela, também não é observada, uma vez que os caracteres são visualizados de forma serrilhada. Entretanto, vale ressaltar que esse é um processo feito principalmente para visualização em telas de computadores e dispositivos móveis, e estes estudos geralmente não contemplam os dispositivos que permitem a visualização em aparatos de realidade virtual.

A partir da análise realizada, observa-se que a aplicação da tipografia ainda pode assumir melhor as características dos ambientes de realidade virtual para expandir suas aplicações. Existe um potencial a ser desenvolvido ao considerar a tipografia no contexto do livro digital com recursos de realidade virtual a fim de tornar a leitura mais adequada e agradável nestes ambientes.

Ademais, foi possível identificar a tipografia como parte do processo de interação na navegação e manipulação. Entretanto, identifica-se a possibilidade de utilizar este recurso também quanto à seleção, utilizando a tipografia para auxiliar o usuário a identificar o objeto a ser manipulado e como recurso de confirmação da seleção.

\section{Considerações finais}

Os livros passaram por diversas transformações tendo em vista o avanço das interfaces gráficas e a popularização dos dispositivos móveis, permitindo a ampliação de experiências para o leitor e a utilização de diferentes recursos para a leitura de livros, entre eles, a possibilidade de expansão para a realidade virtual e aumentada. Com a disseminação da tecnologia, estes recursos têm se tornado cada vez mais acessíveis podendo ser identificados para uso em diversas situações.

Mesmo com diversos recursos presentes no livro digital, o texto ainda é dos principais elementos de composição utilizado para transmitir as informações, e, mesmo publicações baseadas em imagens, devem possuir um refinamento do texto para garantir a qualidade do produto. Sendo assim, a tipografia, responsável por compor textos, tornase fundamental para o design de livros digitais.

Percebeu-se a partir da análise da tipografia em
Realização:
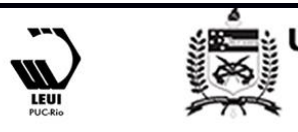


\section{$16^{\circ}$ \\ ERGODESIGN USIHC CINAHPA}

$16^{\circ}$ Ergodesign - Congresso Internacional de Ergonomia e Usabilidade de Interfaces Humano Tecnológica: Produto, Informações Ambientes Construídos e Transporte

$16^{\circ}$ USIHC - Congresso Internacional de Ergonomia e Usabilidade de Interfaces Humano Computador

CINAHPA | 2017 - Congresso Internacional de Ambientes Hipermídia para Aprendizagem. livros digitais acessados a partir de recursos de realidade virtual que a tipografia ainda pode ser melhor planejada. Em diversos momentos, a visualização a partir do recurso de realidade virtual tornou as letras imprecisas e em alguns momentos até mesmo ilegíveis.

Apesar disso, pode-se concluir que a tipografia tem um vasto potencial para auxiliar a interação com o ambiente RV quanto à manipulação, navegação e seleção de objetos. Sendo assim, pode-se inferir que o refinamento da tipografia em livros com recurso de realidade virtual é fundamental.

\section{BIBLIOGRAFIA}

ACIOLY, Angélica de S. G; et. al. "A utilização da realidade virtual em análises ergonômicas e de usabilidade de embalagens - uma revisão de literatura", p. 3649-3660 . In: Anais do 11 Congresso Brasileiro de Pesquisa e Desenvolvimento em Design. São Paulo: Blucher, 2014.

BRUJIN, M.; et al. From print to ebooks a hybrid publishing toolkit for the arts.

Amsterdam, 2015.

CALDWELL, Cath; ZAPPATERRA,

Yolanda. Design editorial. Jornais e revistas Mídia impressa e digital. São Paulo: Gustavo Gili, 2014.

FARIAS, Priscila. Notas para uma normatização da nomenclatura tipográfica. Anais do $P \& D$ Design 2004 - $6^{\circ}$ Congresso Brasileiro de Pesquisa e Desenvolvimento em Design. FAAP: São Paulo.

FARIAS, Priscila. Tipografia digital: o impacto das novas tecnologias. 4. ed. Teresópolis: $2 \mathrm{AB}$, 2013.

GOOGLE, 2016. Disponível em

<https://vr.google.com/cardboard/> Acesso em: 05 nov. 2016

HEITLINGER, Paulo. Cadernos de Tipografia No. 2. Portugal, 2007.
KALBACH, James. Design de navegação web. Porto Alegre: Bookman, 2009.

LUPTON, Ellen. Tipos na tela. São Paulo: Gustavo Gili, 2015.

MURRAY, Janet. Hamlet no Holodeck - O futuro da narrativa no ciberespaço. São Paulo: Itaú Cultural: Unesp, 2003.

PINHEIRO, M.C.S.A. (2012) - Tipografia inclusiva e legibilidade. Convergências: Revista de Investigação e Ensino das Artes. ISSN 16469054. N. ${ }^{\circ} 10$.

PINSKY, Luciana. Os editores e o livro digital. In: Revista do núcleo de estudos do livro. 2013.

PRODANOV, Cleber C.; FREITAS, Ernani C.. Metodologia do trabalho científico. Métodos e Técnicas da Pesquisa e do Trabalho Acadêmico. 2ed. Novo Hamburgo: Feevale Editora. 2013.

RIBEIRO, Nuno. Multimédia e Tecnologias interativas. Lisboa: FCA, 2012. 5. edição atualizada.

\section{ROGERS, SHARP, J. PREECE. Design de}

Interação. Além da Interação Homem-

computador. Porto Alegre: Bookman, 3a Ed. 2013

ROYO, Javier. Design digital. São Paulo: Rosari, 2008.

SALAVERRÍA, R. Multimedialidade: Informar para cinco sentido. In CANAVILHAS, J.

Webjornalismo: 7 características que marcam a diferença. 2014.

SAMARA, Timothy. Guia de design editorial. Porto Alegre: Bookman, 2011.

SCHLATTER, Tania; LEVINSON, Deborah.

Visual Usability. Principles and practices for designing digital applications. Morgan

Kaufmann, 2013.

SILVA, Ana Catarina; BORGES, Maria Manuel. Book design program: a transition to a hybrid
Realização:

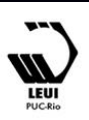




\section{$16^{\circ}$}

ERGODESIGN USIHC CINAHPA $16^{\circ}$ Ergodesign - Congresso Internacional de Ergonomia e Usabilidade de Interfaces Humano Tecnológica: Produto, Informações Ambientes Construídos e Transporte

$16^{\circ}$ USIHC - Congresso Internacional de Ergonomia e Usabilidade de Interfaces Humano Computador

CINAHPA | 2017 - Congresso Internacional de Ambientes Hipermídia para Aprendizagem.

publishing context. Information Services \& Use, IOS Press, v. 31, p. 189-197, 2011.

Teixeira, Deglaucy Jorge; Gonçalves, Berenice Santos; "Interatividade e imersão em narrativa digital de ebook interativo infantil", p. 696-709. In: C. G. Spinillo; L. M. Fadel; V. T. Souto; T. B. P. Silva \& R. J. Camara (Eds). Anais do $\mathbf{7}^{\circ}$

Congresso Internacional de Design da Informação. São Paulo: Blucher, 2015.

TORI, Romero; KIRNER, Claudio. Fundamentos da realidade virtual. In TORI, R.; et al. Fundamentos e tecnologia da realidade virtual e aumentada. Belém, 2006.

VIRGINIO, R.; ALMEIDA, F. Do códice ao leitor digital: a reconfiguração do livro na cibercultura. In NICOLAU, M. O livro digital e suas múltiplas perspectivas. João Pessoa: Ideia editor, 2014.

ZAMBARDA, Pedro. Perônio, jogo infantil "três em um", é finalista da Vuforia Awards da Qualcomm. Geração Gamer. 2015. Disponível em $<$

https://geracaogamer.com/2015/08/20/peroniojogo-infantil-tres-em-um-e-finalista-da-vuforiaawards-da-qualcomm/> Acesso em: 17 de out.

WALKER, Sue. The songs the letters sing: typography and children's reading. Reading: National Centre for Language and Literacy, 2005. 